\title{
TWO-PHASE FLOW AND BOILING OF R245FA IN A 1 MM PRESSING DEPTH PLATE HEAT EXCHANGER - PART I: ADIABATIC PRESSURE DROP
}

\author{
F. Vakili-Farahani, ${ }^{1,2, *}$ R. L. Amalfi, ${ }^{1}$ \& J. R. Thome ${ }^{1}$ \\ ${ }^{1}$ Laboratory of Heat and Mass Transfer, LTCM, École Polytechnique Fédérale de Lausanne, Station \\ 9, CH-1015 Lausanne, Switzerland \\ ${ }^{2}$ Laboratory for Advanced Materials Processing, Swiss Federal Laboratories for Materials Science \\ and Technology (Empa), Feuerwerkerstrasse 39, CH-3602 Thun, Switzerland
}

*Address all correspondence to F. Vakili-Farahani, E-mail: farzad.vakilifarahani@empa.ch

\begin{abstract}
This article is the first in a two-part study on two-phase flow of R245fa in a promising, new compact plate heat exchanger (PHE) design. Two extremely thin corrugated stainless steel plates ( $0.15 \mathrm{~mm}$ thick) having a pressing depth of only $1 \mathrm{~mm}$ and a chevron angle of $65^{\circ}$ were assembled together to make a single-pass refrigerant flow passage, electrically heated PHE prototype for the tests. This test section was then used to investigate its mean and local thermal-hydraulic performance. In Part I, upward single-phase and two-phase adiabatic experiments were carried out to investigate total frictional pressure drops over the PHE, while in Part II the heat transfer characteristics were studied. Besides the traditional approach of measuring pressure drops with a differential transducer, a thermal (infrared) camera was used to measure the local plate surface temperatures during the two-phase adiabatic tests and thus the corresponding local pressures were indirectly obtained within the PHE. Measurements were made over a range of saturation temperatures (19 to $35^{\circ} \mathrm{C}$ ), mass fluxes (10 to $\left.40 \mathrm{~kg} \mathrm{~m}^{-2} \mathrm{~s}^{-1}\right)$, and vapor qualities $(0.05$ to 0.8$)$ to consider their influences on two-phase pressure drop within the PHE. Several of the most widely used prediction methods in the PHE literature were evaluated with respect to the present experimental databases. Then, a new prediction method was proposed capturing all the data in a range of $\pm 30 \%$ with $11.4 \%$ MAE.
\end{abstract}

KEY WORDS: two-phase flow, plate heat exchanger, flow boiling heat transfer, pressure drop, R245fa

\section{INTRODUCTION}

Plate heat exchangers (PHEs) have increasingly become the heat exchanger of choice in many industrial and domestic applications because they are compact, flexible for accommodating a wide range heat load capacities by simply adding or removing plates, easy to clean (e.g., the gasketed PHE), and attractive to enhance heat transfer characteristics (Bergles et al., 1996; Kaka et al., 2002). A chevron PHE is schematically shown in Fig. 1, while representing the lateral and transversal cross-sectional area of the channels for the plates with chevron angles of $\beta=0^{\circ}$ and $\beta=90^{\circ}$, respectively.

Two-phase frictional pressure drops within PHEs have been addressed in several research studies in the PHE literature. These results were mostly pertinent to nonadiabatic processes (i.e., data taken during condensation or evaporation tests) while adiabatic two-phase data are also important for the development of improved prediction methods. For instance, Tribbe and Mller-Steinhagen (2001) conducted a series of experiments to measure pressure drop during steady-state adiabatic two-phase air/water flow in the plate-and-frame heat exchangers with symmetric $\left(30^{\circ} / 30^{\circ}\right.$ and $\left.60^{\circ} / 60^{\circ}\right)$ and mixed $\left(30^{\circ} / 60^{\circ}\right)$ arrangements. They discovered a near-linear relationship between pressure drop and flow quality, particularly at high qualities, while the maximum observed in pipe flow was absent in PHEs. 


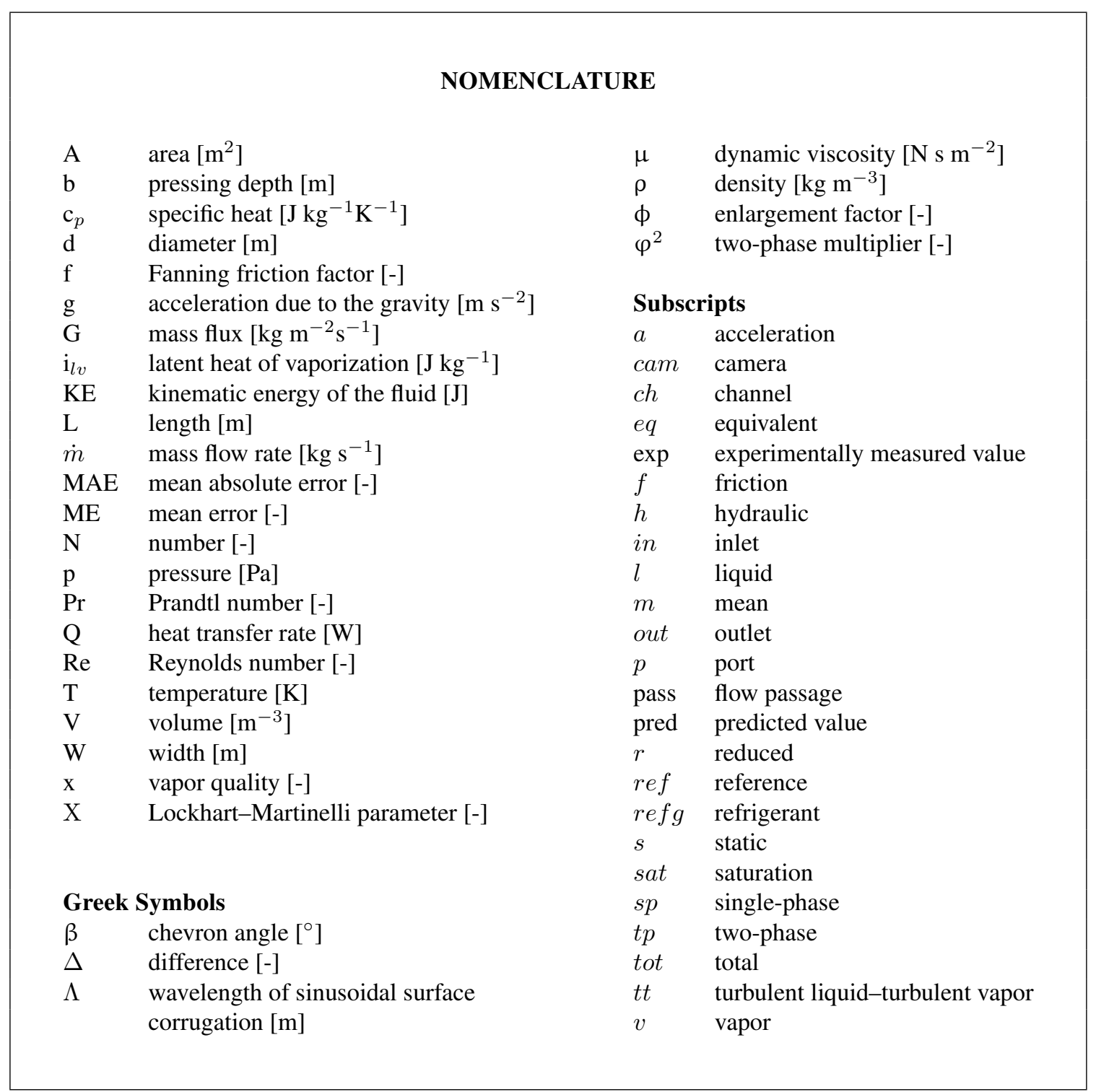

Ayub (2003) has presented a literature survey on PHE studies; however, it was mostly concentrated on the singlephase flow studies and the relevant correlations. They correlated the evaporation pressure drop data of various installed evaporators (mainly operating with ammonia as the working fluid) in terms of the Fanning friction factor:

$$
f=\left(n / \operatorname{Re}^{m}\right)\left(-1.89+6.56 R-3.69 R^{2}\right) \quad 30 \leq \beta \leq 65
$$

where

$$
\begin{aligned}
& R=\left(\frac{30}{90-\beta}\right) \\
& m=0.137 \quad n=2.99 \quad \operatorname{Re} \leq 4000 \\
& m=0.172 \quad n=2.99 \quad 4000<\operatorname{Re} \leq 8000 \\
& m=0.161 \quad n=3.15 \quad 8000<\mathrm{Re} \leq 16000 \\
& m=0.195 \quad n=2.99 \quad \operatorname{Re}>16000
\end{aligned}
$$



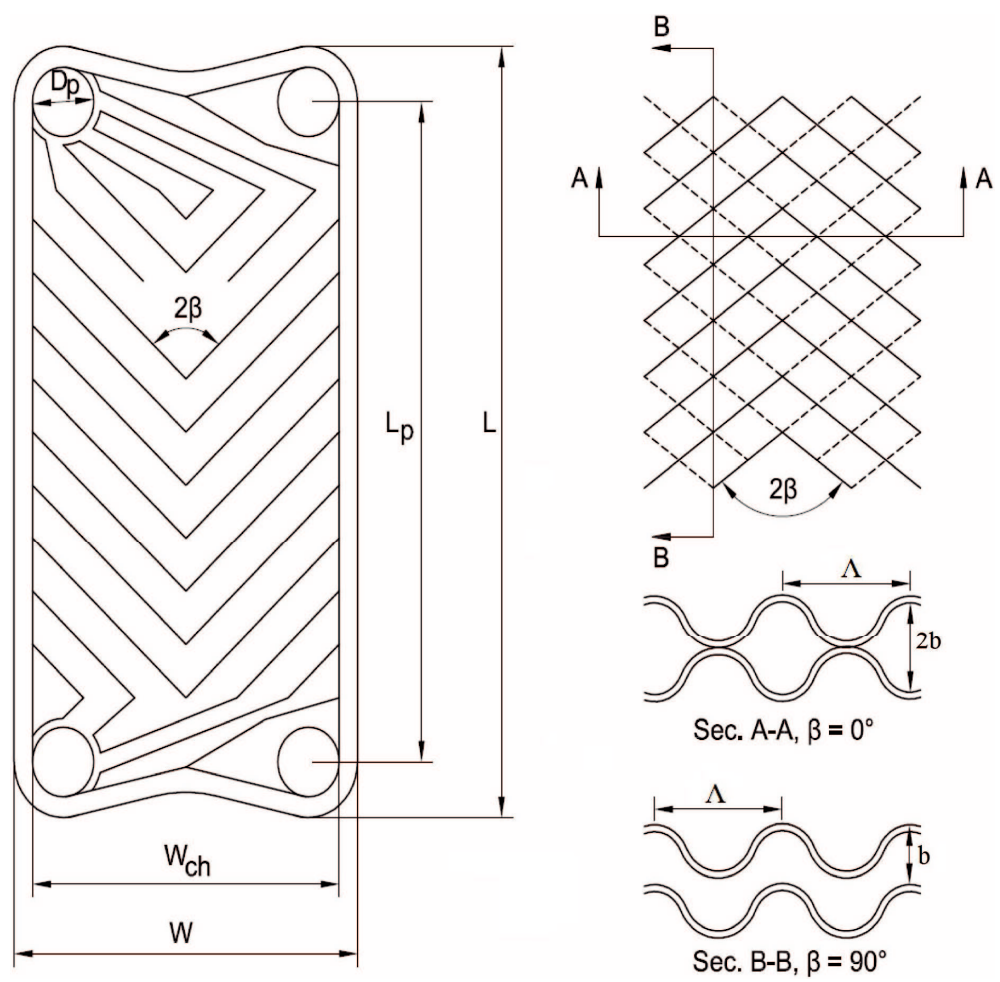

FIG. 1: Schematic of a chevron plate heat exchanger

Han et al. (2003) did flow boiling experiments with refrigerants R410a and R22 in PHEs with chevron angles of $45^{\circ}, 55^{\circ}$, and $70^{\circ}$ and corrugation pitches of $7,5.2$, and $4.9 \mathrm{~mm}$. They correlated their two-phase frictional pressure drops data with respect to the equivalent Reynolds and some geometric parameters:

$$
f_{t p}=\mathrm{Ge}_{3} \mathrm{Re}_{e q}^{\mathrm{Ge}_{4}}
$$

where the geometric parameters are defined as

$$
\mathrm{Ge}_{3}=64710\left(\frac{\Lambda}{d_{h}}\right)^{-5.27}\left(\frac{\pi \beta}{180}\right)^{-3.03}, \mathrm{Ge}_{4}=-1.314\left(\frac{\Lambda}{d_{h}}\right)^{-0.62}\left(\frac{\pi \beta}{180}\right)^{-0.47}
$$

in which $\operatorname{Re}_{e q}$ was defined as in Akers et al. (1959):

$$
\operatorname{Re}_{e q}=\frac{G_{e q} d_{h}}{\mu_{l}}, \quad G_{e q}=G\left[(1-x)+x\left(\frac{\rho_{l}}{\rho_{v}}\right)^{0.5}\right]
$$

Nilpueng and Wongwises (2010) investigated pressure drops of air/water two-phase flow in a nonsymmetrical $50^{\circ} / 10^{\circ} \mathrm{PHE}$ and proposed the following correlation for predicting the two-phase multiplier:

$$
\varphi_{l}^{2}=1.339+\frac{4.492}{\mathrm{X}}
$$

Huang et al. (2012) considered performance characteristics of several industrial PHEs used as liquid over-feed evaporators. Their two-phase frictional pressure drop data for R134a and R507A were correlated using the homogeneous concept:

$$
f_{t p}=\frac{1}{4} \frac{3.81 \times 10^{4} F_{R}}{\left(G d_{h} / \mu_{t p}\right)^{0.9}\left(\rho_{l} / \rho_{v}\right)^{0.16}}
$$


where the two-phase viscosity and density were defined as proposed by Dukler et al. (1964):

$$
\begin{aligned}
\mu_{t p} & =\rho_{m}\left[x_{m} \mu_{v} / \rho_{v}+\left(1-x_{m}\right) \mu_{l} / \rho_{l}\right] \\
\rho_{m} & =\left[x_{m} / \rho_{v}+\left(1-x_{m}\right) / \rho_{l}\right]^{-1}
\end{aligned}
$$

and the geometrical parameter $\mathrm{F}_{R}$ was correlated as

$$
F_{R}=0.183 R^{2}-0.275 R+1.1 \quad R=\beta / 30
$$

Longo (2012) considered complete vaporization of R1234yf inside a brazed PHE. They reported a linear relationship between their frictional pressure drop gradient data and the kinetic energy per unit volume of the refrigerant flow:

$$
\Delta p_{f} / L \quad\left[\mathrm{kPam}^{-1}\right]=5.25 \mathrm{KE} / V \quad\left[\mathrm{~J} \mathrm{~m}^{-3}\right]
$$

Khan et al. (2012) investigated pressure drops of ammonia during evaporation in a symmetric $60^{\circ} / 60^{\circ}$ commercial PHE. They found that the pressure drop was strongly influenced by the equivalent Reynolds number while the effect of saturation temperature was moderate, and correlated the two-phase friction factor as follows:

$$
f_{t p}=212 \operatorname{Re}_{e q}^{-0.51} p_{r}^{0.53}
$$

The principal objective of the present two-part study is to develop and experimentally investigate a more compact, less expensive PHE design. To this end, new stainless steel plates were developed with a thickness of only $0.15 \mathrm{~mm}$ (60\% thinner than conventional $0.60 \mathrm{~mm}$ plates), thus significantly reducing the unit cost per heat transfer surface area. Second, the corrugation depth was reduced to only $1 \mathrm{~mm}$ (compared to conventional 3 to $5 \mathrm{~mm}$ depths), making the stack only $1 / 3$ the volume or less compared to a conventional stack, which also reduces the refrigerant charge in the unit. However, little information is currently available for two-phase flow heat transfer and pressure drops within PHEs with very shallow corrugation depths, which justifies the current experimental investigation of twophase pressure drop phenomena in PHEs. As a consequence, in the present paper single-phase and two-phase pressure drops within this more compact PHE are reported, for a plate having a pressing depth of only $1 \mathrm{~mm}$ and a chevron angle of $65^{\circ}$, experimentally investigated through a series of adiabatic tests. Several existing and most widely used two-phase prediction methods have been evaluated based on the present database and a new prediction method was then proposed to reproduce the current data. In addition to the total pressure drops, a thermal camera has been used to measure the plate surface temperatures with high resolution and then the data were reduced to obtain the local pixel-by-pixel two-phase pressures along the PHE to investigate pressure profiles along and widthwise on the test section.

\section{EXPERIMENTAL SETUP AND PROCEDURE}

\subsection{Test Facility}

A test facility was built in the LTCM (Laboratory of Heat and Mass Transfer at École Polytechnique Fédérale de Lausanne) to specifically investigate high-resolution local evaporation heat transfer and pressure drops of R245fa within a more compact PHE prototype.

Figure 2 shows an image of the test stand together with the corresponding schematic diagram. The experimental test facility consists of several primary components: a new promising prototype plate test section (evaporator), a pump, a condenser, a reservoir, power supplies, a Coriolis mass flow meter, pressure and temperature measuring instrumentation, an IR camera, and a computerized data acquisition system.

The subcooled refrigerant from the condenser was circulated within the circuit by an oil-free magnetic driven micro gear pump. The gear pump was magnetically coupled to a variable speed electric motor to control the refrigerant flow, whose mass flow rate was measured using a Coriolis mass flow meter. The electrical preheater was used to set the desired inlet condition to the PHE test section. Two-phase adiabatic pressure drops within PHE were mostly focused on here and in those cases the refrigerant was always partially evaporated within the preheater in order to maintain the 


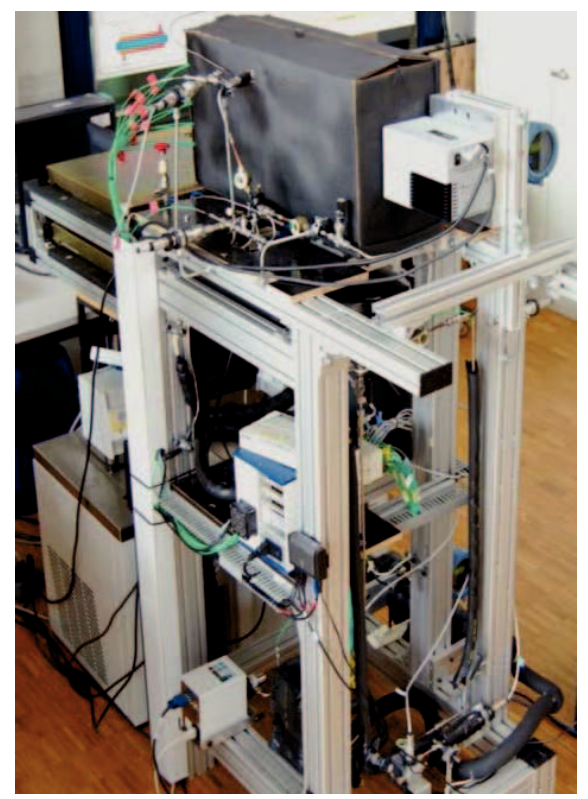

(a)

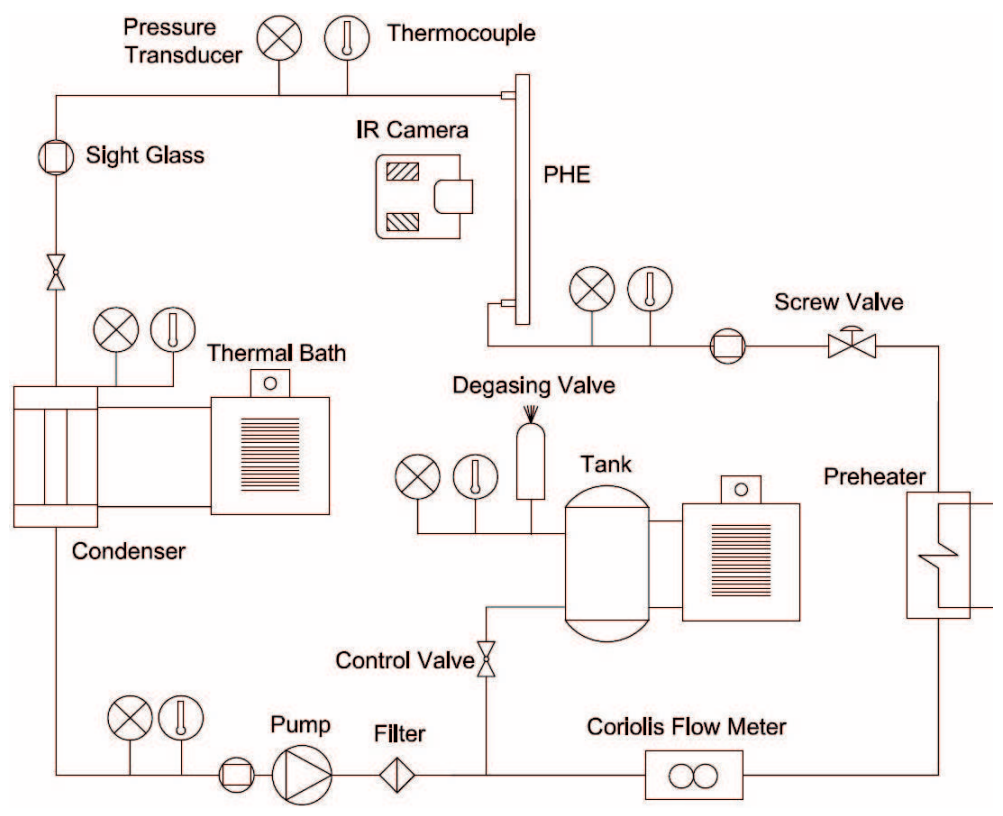

(b)

FIG. 2: Experimental test facility (a) image of test stand, (b) schematic diagram

desired inlet test condition. Additionally, a screw valve was installed upstream of the preheater and test section (plate prototype) to provide sufficient pressure drop to block back flows and suppress possible flow instabilities.

The test section (evaporator) was composed of two extremely thin corrugated stainless steel plates, which were laser spot welded together around their common perimeter, and inlet and outlet tubular ports were also laser welded into place in their respective openings in one of the plates. This process created a single flow passage between the two plates for the refrigerant flow, while a PVC frame box was designed to enclose, support and insulate these two plates during the operating conditions. The test section was leak tested and thus proven to be leak-proof. Furthermore, a thermographic IR camera from FLIR (Therma-CAM SC 3000) was set up to measure the local surface temperatures for one of the plates

Next in the two-phase flow circuit, the fluid was fully condensed in another plate heat exchanger, employing a counter-current cold-water stream, before going back to the pump. Moreover, the unit was equipped with one thermal bath to externally control the refrigerant temperature in the reservoir and the operating system pressure accordingly. The pressure transducers (absolute and differential) and thermocouples were installed at appropriate locations just before and after the test section to measure the corresponding fluid pressures and temperatures. High-pressure safety valves, a micro-filter, and a degassing valve were utilized for maintaining safe operation. A National Instrument (NI) data acquisition system was employed to record the measured temperatures, pressures, flow rate, and the signals from the IR camera. Also, the test facility was fully automated through a PC using Labview.

\subsection{PHE Test Section}

The PHE prototype to be tested is assembled from two extremely thin corrugated stainless steel plates with a high chevron angle but a moderate enlargement factor. The geometric specifications of the plate are listed in Table 1, while the two plates and welds are shown in Fig. 3. A PVC-supporting frame box was designed and fabricated to enclose the plates, as it substantially fortifies the plates to hold the internal pressure of the refrigerants and insulates the plates during operation. The test section was set up for vertical flow, with the test fluid entering the bottom and exiting from 
TABLE 1: Geometry and size of the PHE used in present study

\begin{tabular}{|c|c|}
\hline Parameter & Measured \\
\hline Length & $257 \mathrm{~mm}$ \\
\hline Width & $50 \mathrm{~mm}$ \\
\hline Port-to-port length & $228 \mathrm{~mm}$ \\
\hline Plate thickness & $0.15 \mathrm{~mm}$ \\
\hline Inlet/outlet port diameter & $6 \mathrm{~mm}$ \\
\hline Chevron angle & $65^{\circ}$ \\
\hline Corrugation pitch & $3.7 \mathrm{~mm}$ \\
\hline Pressing depth & $1 \mathrm{~mm}$ \\
\hline Enlargement factor & 1.17 \\
\hline Hydraulic diameter & $1.7 \mathrm{~mm}$ \\
\hline Equivalent diameter & $2 \mathrm{~mm}$ \\
\hline Flow cross-section area & $50 \mathrm{~mm}^{2}$ \\
\hline
\end{tabular}

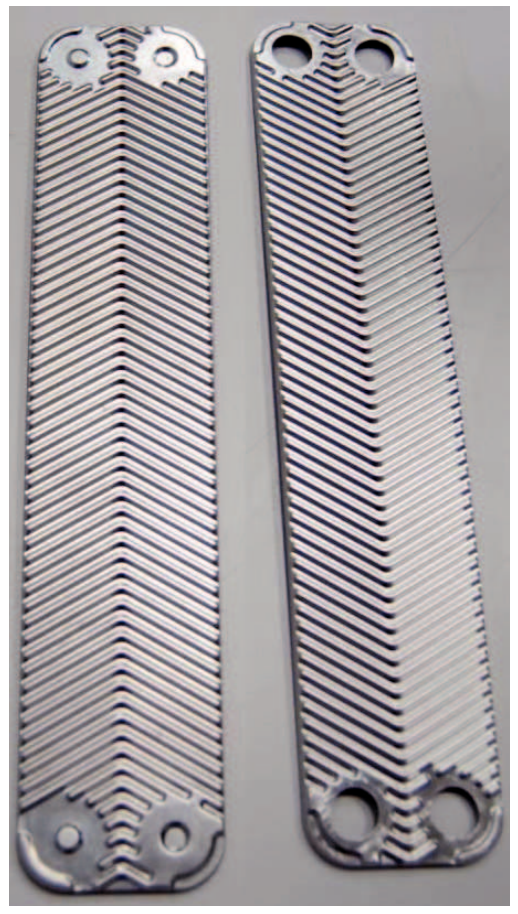

(a)

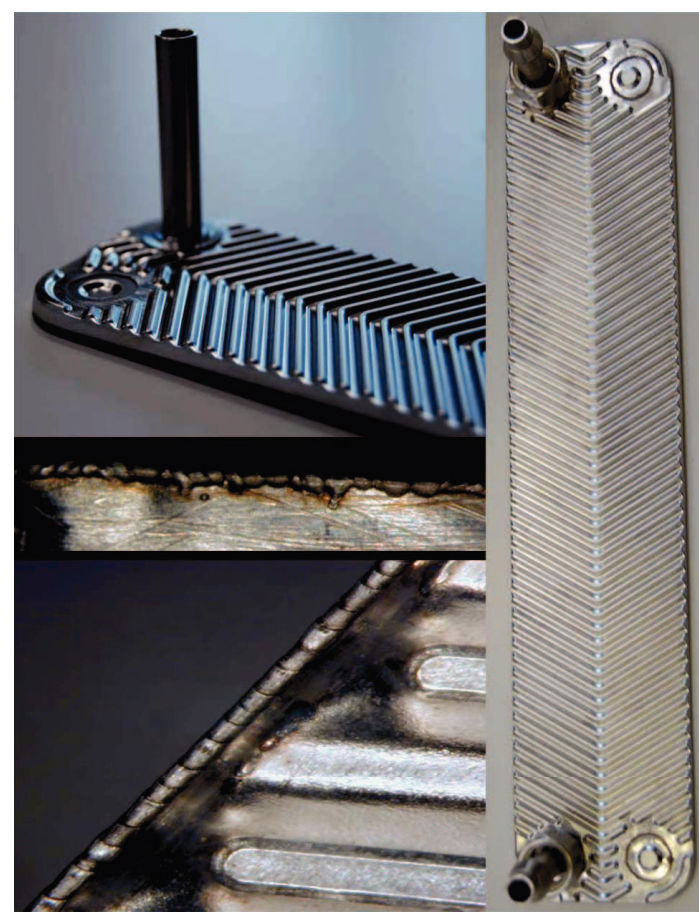

(b)

FIG. 3: Image of plate prototype (a) before assembling, (b) after laser-hybrid welding

the top. Six "windows" (rectangular openings) were created in one side of the frame in order to measure plate surface temperature using a thermographic/IR camera (Fig. 4).

The test section was designed to perform thermal visualization of the fluid flow as well as locally investigate twophase adiabatic pressure drops and flow boiling phenomena all around the plate. Therefore, a single-pass refrigerant 


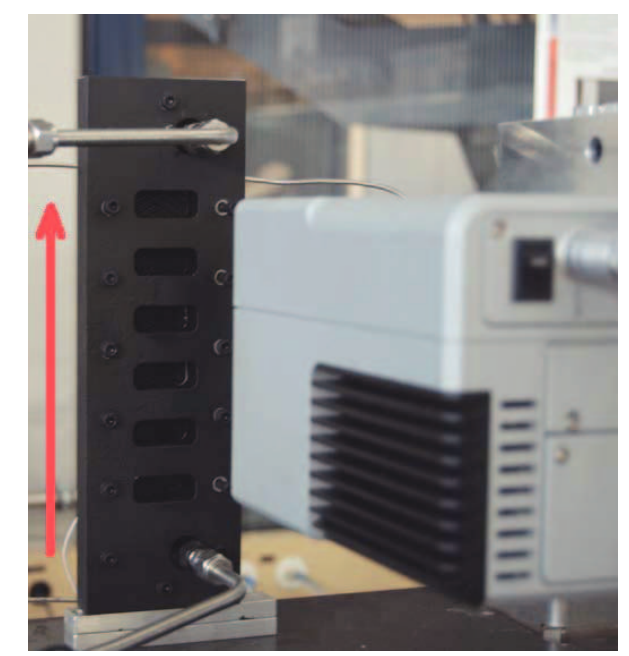

FIG. 4: Photograph of the test section enclosed in PVC frame box and set up on the facility; PHE front view with the arrow showing the flow direction

flow passage PHE was made. Electrical current from a DC power supply (Sorensen DCS8-125E) was directly applied to the plates in order to mimic evaporation in a PHE (results are presented in Part II); nevertheless, no electrical power was applied during the present two-phase frictional pressure drop tests (i.e., adiabatic tests since the heat conduction and natural convection losses from the PHE test section were negligible by running at or near room temperature). The test section was coated with high-emissivity black paint and enclosed by a box (see Fig. 4) to avoid any undesired disturbances (e.g., irradiation or reflection from/to the surrounding objects).

\subsection{Measurement Systems: Calibration and Accuracy}

While the measurement systems (e.g., thermocouples, absolute and differential pressure transducers, mass flow meter, IR camera, and data acquisition system) were calibrated by the manufacturer, they were again calibrated here over the present experimental range after installation in the test loop and prior to starting the experiments. Instead, for the Coriolis mass flow meter, the factory calibration has been used. All fluid thermodynamic and transport properties have been computed using the NIST REFPROP software (version 9).

The test section dimensions were generally measured using a tape measure with a precision of $1 \mathrm{~mm}$ and a caliper with a precision of $0.01 \mathrm{~mm}$ for more accurate measurements. Accordingly, the greatest possible error (bias) was considered to be one half of the measuring unit; i.e., 0.5 and $0.005 \mathrm{~mm}$, respectively, for the tape measure and caliper.

Two Coriolis mass flow meters were used to measure the refrigerant and water mass flow rates: the Emerson series CMF010 with an accuracy of $0.05 \%$ of the rate for refrigerant flow and the series R050 with an accuracy of $0.5 \%$ of the rate for water flow while both were coupled with a transmitter 1700 .

K-type thermocouples from Thermocoax/Thermocontrol were used in this study. Stainless steel sheathed thermocouples of $1 \mathrm{~mm}$ diameter were used to measure fluid temperatures at several locations through the refrigerant loop. In-house thermocouple calibrations were performed over the applicable test range, in reference to two high-precision PT100 resistance temperature detectors (RTDs) with the bias accuracy of $0.03 \mathrm{~K}$. In addition, the calibration was conducted after connecting the thermocouples to the data acquisition cards, using the same monitoring software with the same averaging and filtering settings, to avoid any discrepancy from the real experiments. The uncertainty of the thermocouple measurements was estimated conservatively to be $\pm 0.1 \mathrm{~K}$.

In the current study, a high-speed IR camera (FLIR Therma-CAM SC 3000) with a maximum frame rate of 900 fps (presently operated at $60 \mathrm{~Hz}$ ), field of view of $20^{\circ} \times 15^{\circ}$, spatial resolution (IFOV) of $1.1 \mathrm{mrad}$, and minimum focus distance of $0.3 \mathrm{~m}$ has been used to accurately measure the local pixel-by-pixel plate surface temperatures from one 
side (front plate) of the test section. The IR camera reads and records the temperature information of $320 \times 240$ pixels at each frame. In the current experiments, the camera was located $0.53 \mathrm{~m}$ away from the plate surface. Therefore, the resolution of every pixel was $0.34 \mathrm{~mm}^{2}$, i.e., a square with a side length of $0.58 \mathrm{~mm}$.

In order to precisely calibrate the IR camera, a set of single-phase adiabatic flow tests was conducted with subcooled refrigerant flowing through the PHE with its inlet temperature adjusted by the preheater. The fluid temperature was measured by the calibrated thermocouples at the PHE inlet and outlet. Then, the reference temperature was concluded to be the average of the inlet to outlet fluid temperature for every individual test condition. These calibration tests were carried out at relatively high flow rates to ensure turbulent flow. This grants a high level of flow mixing and distribution all around flow path between the two plates. The fluid temperature did not change within the PHE from inlet to outlet at any individual test since adiabatic test conditions were established since natural heat convection loss to the ambient was negligible (the PVC-frame box insulated the plates). Furthermore, the plates are extremely thin $(0.15 \mathrm{~mm})$ for which the thermal resistance is negligible as well. Thus, the local fluid temperature is equivalent as the local plate surface temperature. Therefore, flowing subcooled liquid refrigerant within the PHE provides an isothermal condition throughout the plate. Accordingly, the IR camera was carefully calibrated in-house for every individual pixel through adiabatic tests up and down within the relevant range of the current investigation, obtaining an accuracy of $0.15 \mathrm{~K}$. Calibrating in place in this case means that all extraneous effects and influences are included in the calibration, in particular the local angle of the corrugated plate with respect to the camera and the local emissivity of the surface. The test section was placed in a black box to eliminate background changes during the calibrations and subsequent experimental tests.

A sample of an image recorded by the IR camera for an isothermal specific condition (calibration test) is presented in Figs. 5(a) and 5(b), showing, respectively, an uncalibrated and corresponding calibrated thermal map. Generally, a fraction of the pixels located at the edges of the openings might be affected from the surface temperature of the PVC supporting box, instead of the plate surface temperature, and therefore they could be influenced by the PVC support

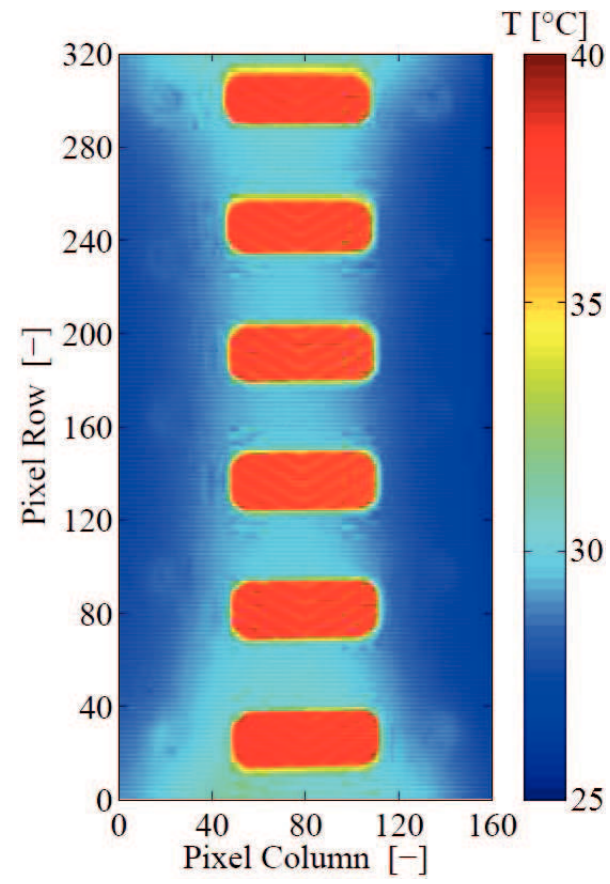

(a)

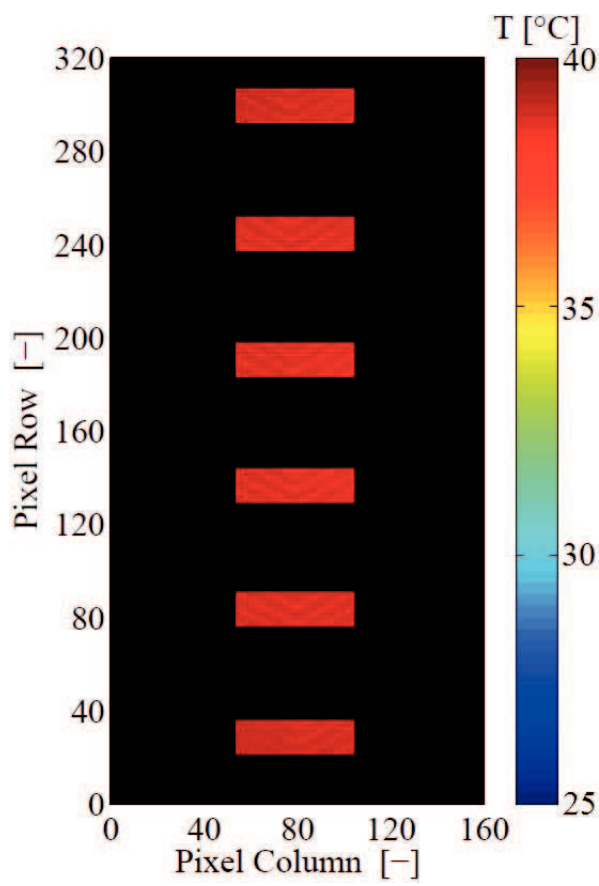

(b)

FIG. 5: Sample of image (thermal map) obtained by IR camera for isothermal (adiabatic) test; (a) uncalibrated map, (b) calibrated thermal map 
box. Accordingly, the first lines of the pixels located next to the opening edges were excluded through the calibration instruction. This makes the calibrated sight openings become rectangular and thus smaller than those of the original images.

Repeating the isothermal tests at several intervals over the range of calibration provides the appropriate database to make calibration curve fittings for each individual pixel located in the sight openings. Furthermore, the adiabatic subcooled liquid flow tests were performed prior and subsequent to the experimental campaign in order to prove that there was no readable drift in the IR camera's calibration. The results were respectively termed as pre- and postcalibration. Figure 6 shows a sample of pre- and post-calibration test results (points) together with the corresponding calibration correlation (the curve fitted to the data) for a designated pixel located in the second opening from the top (column 80, row 250). As can be observed, there was no drift from the pre- to post-calibrations tests. Similar results were also obtained for all the pixels located inside of the six sight openings.

The fluid pressures were measured at several locations in the main loop (e.g., at the inlet and outlet of the test section) using absolute pressure transducers: Series $33 \mathrm{X}$ from Keller with a full-scale reading of 10 bar. The pressure sensors were precisely calibrated over the applicable range with a pneumatic dead weight tester from Yantrika with the accuracy $\pm 0.015 \%$ of reading. The resulting calibration accuracy was better than $\pm 220 \mathrm{~Pa}$.

In addition, a differential pressure transducer from Endress+Hauser series Deltabar S PMD75 with a maximum range of 500 mbar was utilized to measure the total pressure drop over the test section. The sensor was carefully calibrated with an uncertainty of $\pm 20 \mathrm{~Pa}$, using a U-tube manometer filled with isopropyl alcohol (liquid density of $789 \mathrm{~kg} / \mathrm{m}^{3}$ at $20^{\circ} \mathrm{C}$ ).

A series of single-phase tests (remaining in a turbulent refrigerant flow condition) was conducted first, prior to starting the targeted experiments in order to calibrate the heat losses in the preheaters and the test section (the PHE). Accordingly, the heat and mass fluxes were changed in order to survey the energy balance between refrigerant flow and electrical input power. The difference was realized as the total loss:

$$
Q_{\text {loss }}=Q_{\text {in }}-\dot{m} c_{p}\left(T_{\text {refg, out }}-T_{\text {ref } g, \text { in }}\right)
$$

Finally, the heat loss was deduced to be only a function of wall surface temperature for the preheaters (see Fig. 7). Therefore, the losses in the preheater were found to be mainly associated with heat conduction and natural convection to the surrounding. However, for the PHE test section, the relative heat losses through conduction and natural convection to the surrounding were negligible (no power applied to the PHE test section during the adiabatic two-phase pressure drop tests). Therefore, the heat loss in the preheaters was correlated with respect to the tube wall temperatures

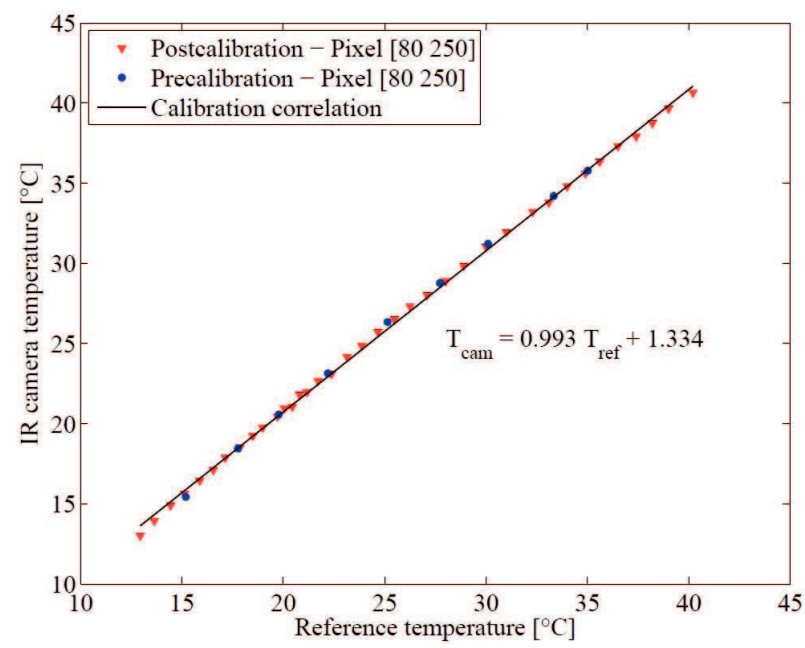

FIG. 6: Sample of pre-calibration (red) and post-calibration (blue) results for pixel (80,250); $\mathrm{T}_{r e f}$ represents reference/refrigerant temperature and $\mathrm{T}_{\text {cam }}$ represents the value measured by IR camera 


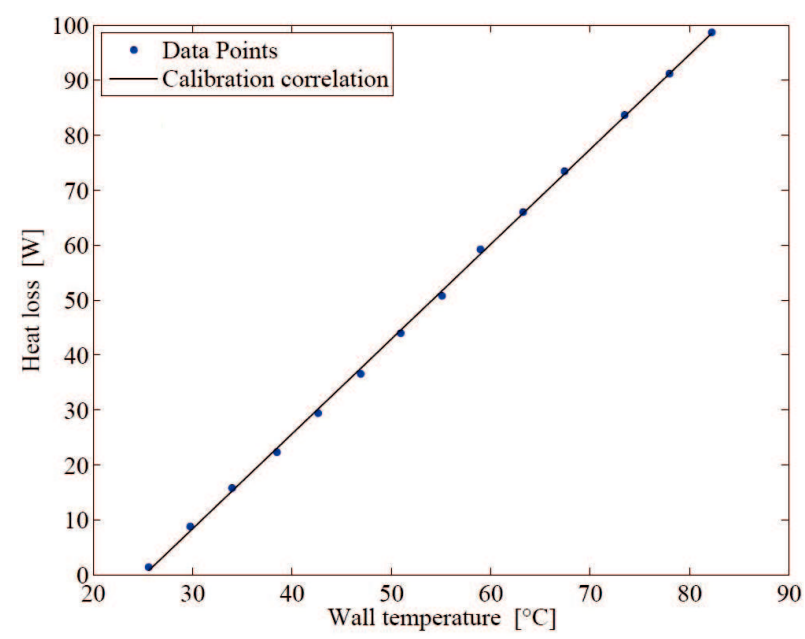

FIG. 7: Heat loss in preheater correlated with wall temperature

and the results were then used to determine the actual power delivered to the refrigerant flow and the refrigerant vapor quality.

A National Instruments (NI) data acquisition system was employed to acquire the measurements. In addition, the test facility was fully automated through a PC using Labview. To avoid the electrical noise of the $50 \mathrm{~Hz}$ AC power, 100 samples taken at a $1000 \mathrm{~Hz}$ rate (i.e., $0.1 \mathrm{~s}$ ) are gathered and averaged to produce one data point. Labview software is used to monitor and record the data.

\subsection{Uncertainty Analysis}

In general, uncertainty (U) is defined as an interval, about the measured value, that has the probability of containing the true value. The uncertainty interval in the measurements is composed of both systematic error, which is a bias/fixed error (B), and precision error, which can be a random error (P), as the uncertainty components. Although the true systematic/fixed error is unknown, B is estimated so that it represents the limits of a $95 \%$ confidence interval for the possible true systematic error. The bias error can be estimated through interlaboratory calibration tests or taken from the instrumentation documentation given by the manufacturer. However, the random error may be estimated by inspection of the measurement scatter (i.e., the population standard deviation) since it introduces variation or scatter in repeated measurements of a parameter. For $95 \%$ confidence, all random uncertainty sources can be estimated as twice the standard deviation of the mean $\left(P=2 S_{\bar{x}}\right)$. Therefore, the total uncertainty interval in the measurements with $95 \%$ confidence level, $\mathrm{U}_{95}$, is calculated by

$$
U_{95}=\sqrt{B^{2}+\left(2 S_{\bar{x}}\right)^{2}}
$$

where the standard deviation of the mean of $n$ measurements is defined as

$$
S_{\bar{x}}=\frac{S_{x}}{\sqrt{n}}
$$

and $S_{x}$ is the standard deviation of a data sample. The accuracy and systematic errors of all instrument were detailed earlier. Accordingly, a summary of systematic uncertainties of the measured parameters is listed in Table 2.

A National Instrument data acquisition system was used to gather information from each sensor. Each data sample was deduced from 100 individual measurements with a rate of $1 \mathrm{kHz}$. To produce a data point of the local surface temperature on the plate, 60 mean IR camera samples were gathered for each experimental measurement (temperatures, 
TABLE 2: Summary of systematic measurement errors

\begin{tabular}{|c|c|}
\hline Measured parameter & Bias error \\
\hline Temperature (thermocouples) & $\pm 0.08 \mathrm{~K}$ \\
\hline Temperature (IR camera) & $\pm 0.15 \mathrm{~K}$ \\
\hline Absolute pressure & $\pm 220 \mathrm{~Pa}$ \\
\hline Differential pressure & $\pm 20 \mathrm{~Pa}$ \\
\hline Mass flow rate & $\pm 0.05 \%$ of rate \\
\hline Dimensions & $\pm 0.005 \mathrm{~mm}$ \\
\hline
\end{tabular}

pressures, and mass flow meters) during 1 min and averaged. Accordingly, the standard deviation of the sample mean was calculated in accordance with Eq. (11) given by the ASME PTC $19.1-1998^{1}$ for $95 \%$ confidence level. IR camera's temperature measurements were taken as a mean value of 600 sequential readings for each pixel recorded at a sampling rate of $60 \mathrm{~Hz}$. Moreover, a rigorous step-by-step uncertainty analysis, as proposed in ASME PTC 19.1-1998, has been followed to evaluate the relevant uncertainty and propagation of the error to the results:

$$
\begin{aligned}
& \Upsilon=f\left(\chi_{1}, \chi_{2}, \chi_{3}, \ldots, \chi_{n}\right) \\
& \delta \Upsilon=\sqrt{\left(\frac{d \Upsilon}{d \chi_{1}} \delta \chi_{1}\right)^{2}+\left(\frac{d \Upsilon}{d \chi_{2}} \delta \chi_{2}\right)^{2}+\left(\frac{d \Upsilon}{d \chi_{3}} \delta \chi_{3}\right)^{2}+\ldots+\left(\frac{d \Upsilon}{d \chi_{n}} \delta \chi_{n}\right)^{2}}
\end{aligned}
$$

where $\delta \chi_{i}$ is total uncertainty of the parameter $\chi_{i}$ which was obtained using Eq. (10). Table 3 presents the total uncertainty and error propagation to the test results.

TABLE 3: Summary of total uncertainty analysis of the results

\begin{tabular}{|c|c|c|}
\hline Parameter & Range & Total uncertainty \\
\hline Vapor quality [-] & $0-0.8$ & $1-5 \%$ \\
\hline Single-phase friction factor [-] & $0.5-3$ & $2-10 \%$ \\
\hline Two-phase friction factor [-] & $1.3-8$ & $3-15 \%$ \\
\hline $\begin{array}{c}\text { Local refrigerant pressures } \\
\text { from IR measurements [bar] }\end{array}$ & $1-2$ & $0.5 \%$ \\
\hline
\end{tabular}

\section{DATA REDUCTION}

In the present study, besides the traditional approach of measuring two-phase pressures and pressure drops using transducers, an experimental approach was introduced in order to investigate high-resolution local two-phase pressure fields of R245fa within the present prototype PHE. The frame enclosing the prototype had six "windows" on one side in order to have IR camera access to measure plate surface temperatures using a thermographic/IR camera (see Figs. 4 and 5). Furthermore, a series of adiabatic tests was conducted to address locally two-phase flow pressure drops within the PHE (pressure field), using temperature measurements from IR camera while ignoring the negligible thermal resistance of the plate wall (i.e., the wall temperatures are equivalent to the fluid's local saturation temperatures and can be used to back out the local saturation pressures from the vapor pressure curve of the fluid). This will be detailed in the following sections.

\footnotetext{
${ }^{1}$ American Society of Mechanical Engineers Performance Test Code, issued Dec. 31, 1998.
} 


\subsection{Single-Phase Pressure Drop Analysis}

A set of adiabatic subcooled flow experiments was conducted first to measure single-phase pressure drops within the PHE. In this case, the subcooled refrigerant at essentially room temperature flowed through the PHE, maintaining an adiabatic condition. Then, the mass flux was changed within a certain range $\left(5-350 \mathrm{~kg} \mathrm{~m}^{-2} \mathrm{~s}^{-1}\right)$ from low to high. The single-phase measured total pressure drop includes the following components: static, friction, inlet/outlet ports, and piping connections with all their fittings and bends (obtained by the differential pressure transducer between inlet/outlet of the PHE):

$$
\Delta p_{\text {tot }}=\Delta p_{s}+\Delta p_{f}+\Delta p_{\text {port }}+\Delta p_{\text {piping }}
$$

The piping and port pressure drops are not part of PHE losses; therefore, they were subtracted from the measured values to retain only the PHE pressure drop. In single-phase tests, the static pressure drop remained constant and it was proportional to the height of liquid refrigerant column in the PHE. However, frictional pressure drop through the PHE and inlet/outlet ports grew with the increase in the refrigerant mass flux as expected. The pressure drop across the inlet and outlet ports was quantified according to the Shah and Focke (1988) correlation:

$$
\Delta p_{\text {port }}=0.75\left[\left(\frac{G_{\text {port }}^{2}}{2 \rho}\right)_{\text {in }}+\left(\frac{G_{\text {port }}^{2}}{2 \rho}\right)_{\text {out }}\right] N_{\text {pass }}
$$

Therefore, the single-phase frictional pressure drops were calculated subtracting other components from the total measured pressure drop. Consequently, the single-phase Fanning friction factors were determined as follows:

$$
f_{s p}=\frac{\Delta p_{f} d_{h} \rho_{l}}{2 L_{p} G^{2}}
$$

\subsection{Two-Phase Pressure Drop Analysis}

The measured total pressure drops in the two-phase flow experiments (obtained by the differential pressure transducer between inlet/outlet of the PHE) consist of several components: the static (gravitational), acceleration (or de-acceleration) and frictional pressure drops inside the channels, pressure drops across the ports, and pressure drops through the piping connections with all their fittings and bends:

$$
\Delta p_{\text {tot }}=\Delta p_{s}+\Delta p_{a}+\Delta p_{f}+\Delta p_{\text {port }}+\Delta p_{\text {piping }}
$$

The static and acceleration pressure losses may be evaluated theoretically using the homogeneous scheme, which gives

$$
\begin{gathered}
\Delta p_{s}=g L_{p}\left[x / \rho_{v}+(1-x) / \rho_{l}\right]^{-1} \\
\Delta p_{a}=G^{2} \Delta x\left(1 / \rho_{v}-1 / \rho_{l}\right)
\end{gathered}
$$

The pressure drops across the evaporator inlet and outlet ports and manifolds are usually evaluated according to the correlation suggested by Shah and Focke (1988) assuming homogeneous flow [Eq. (15)], whereas the inlet and outlet fluid densities $\left(\rho_{i n}\right.$ and $\rho_{\text {out }}$ ) are defined according to the state of the refrigerant at the inlet and outlet ports. For liquid-vapor flow, the two-phase mean density was determined at the respective vapor quality with the following expression:

$$
\rho_{m}=\left[x / \rho_{v}+(1-x) / \rho_{l}\right]^{-1}
$$

In addition, a homogeneous model has been used to estimate the pressure drop through the piping (from pressure gauges to the PHE ports). However, this term always remained negligible relative to the total pressure drop and thus the homogeneous model was found to be sufficient for the current data processing.

Finally, the two-phase frictional pressure drops were determined by subtracting the other components from the total measured pressure drops across the transducer. Consequently, the two-phase Fanning friction factors were determined as follows:

$$
f_{t p}=\frac{\Delta p_{f} d_{h} \rho_{m}}{2 L_{p} G^{2}}
$$


Accordingly, a set of two-phase adiabatic tests was conducted to investigate the pressure field and corresponding drops within the PHE. The vapor qualities were regulated within the desired range $(0.05-0.8)$ utilizing the electrical preheater while no heat was applied to the PHE itself. The pressure drop results, together with the corresponding Fanning friction factors, were determined and used to evaluate the two-phase frictional pressure drop prediction methods. In addition, a new prediction method was suggested based on the current database (presented in the following sections).

Besides the above traditional approach, another scheme has been introduced to indirectly obtain local two-phase pressures (and thus two-phase pressure drops) throughout the PHE, using the temperature measurements from the inhouse calibrated IR camera taken during adiabatic two-phase flow tests. In this case, the local pixel-by-pixel pressures were determined from the corresponding measured wall temperatures using the fluid's vapor pressure curve; that is, the adiabatic liquid-vapor flowed through the PHE and thus the wall temperatures were assumed to be equivalent to the fluid/saturation temperatures ignoring the negligible wall thermal resistance:

$$
p_{\text {sat }} \propto T_{\text {sat }} \cong T_{\text {wall }}
$$

\section{RESULTS AND DISCUSSION}

\subsection{Single-Phase Pressure Drop}

As explained in the data reduction section, single-phase plate pressure drops were quantified by subtracting the pressure drops through the ports and piping from the measured value. The contribution of static and frictional components relative to the total pressure drop within the PHE is depicted in Fig. 8. For the low Reynolds numbers, the static pressure drop made the major contribution, while the friction component became dominant at higher flow rates since the static component remains nearly constant but the frictional pressure drop grows fast with the square of the mass flux. Figure 9 presents the single-phase pressure drops compared to correlations developed for larger corrugation depths (these were only approximately successful) and the new correlation fitted here to $3.7 \%$ MAE:

$$
f_{s p}=64.81 \mathrm{Re}^{-0.875}+0.418
$$

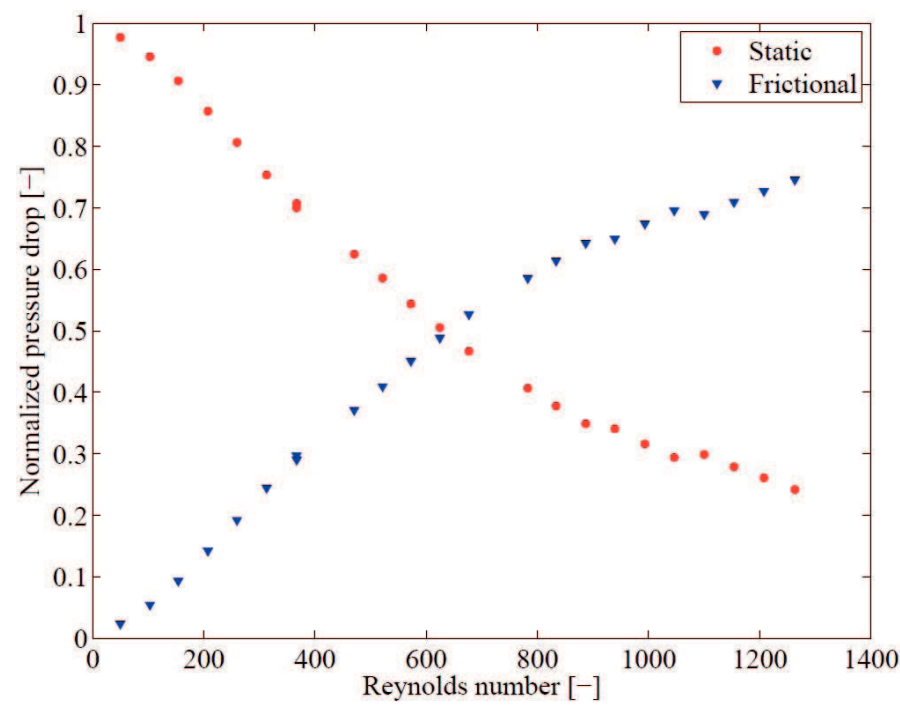

FIG. 8: Contribution of each single-phase pressure drop component; static and friction components normalized based on the total pressure drops within PHE 


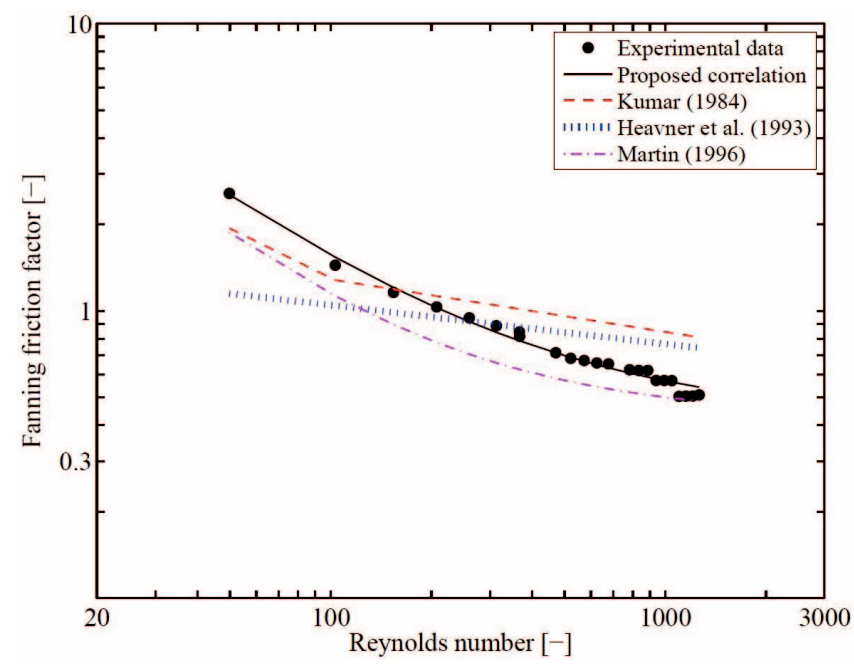

FIG. 9: Single-phase Fanning friction factor compared to the prediction methods

\subsection{Adiabatic Two-Phase Pressure Drop}

The two-phase pressure drops within the PHE were composed of several components: static, momentum, and frictional pressure drop. Here, only the frictional pressure drops have been used to address the influence of the mass flux and system pressure on the adiabatic two-phase pressure drop of refrigerant R245fa in the PHE. Some selected measured data are presented in Fig. 10 to illustrate the trends of frictional pressure drops over the range of vapor quality for various mass fluxes and saturation temperatures. In these plots, each data point represents the result of one individual adiabatic experiment for which the inlet-to-outlet vapor quality remained nearly constant (no heat was transferred within the PHE as natural convection to the room was negligible). However, the vapor quality slightly changed from the inlet to outlet due to the pressure drop as a small flashing effect.

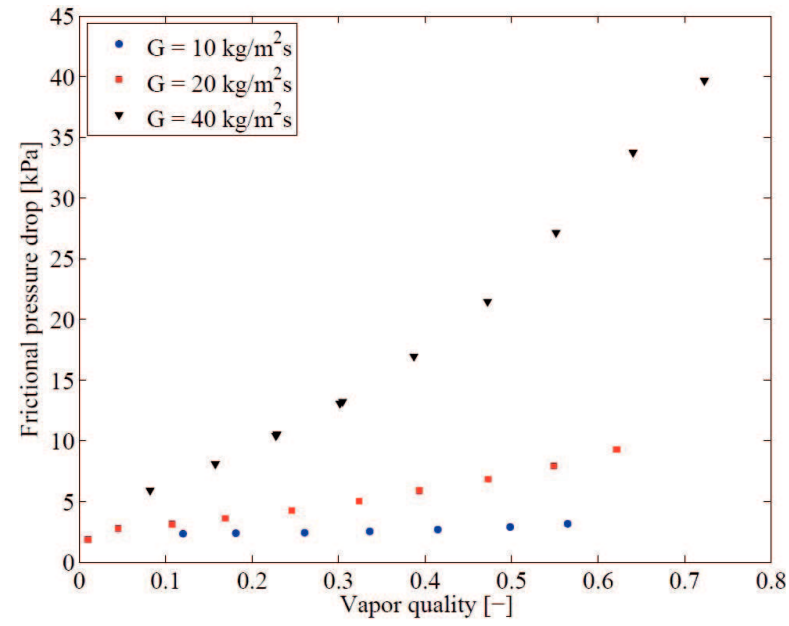

(a)

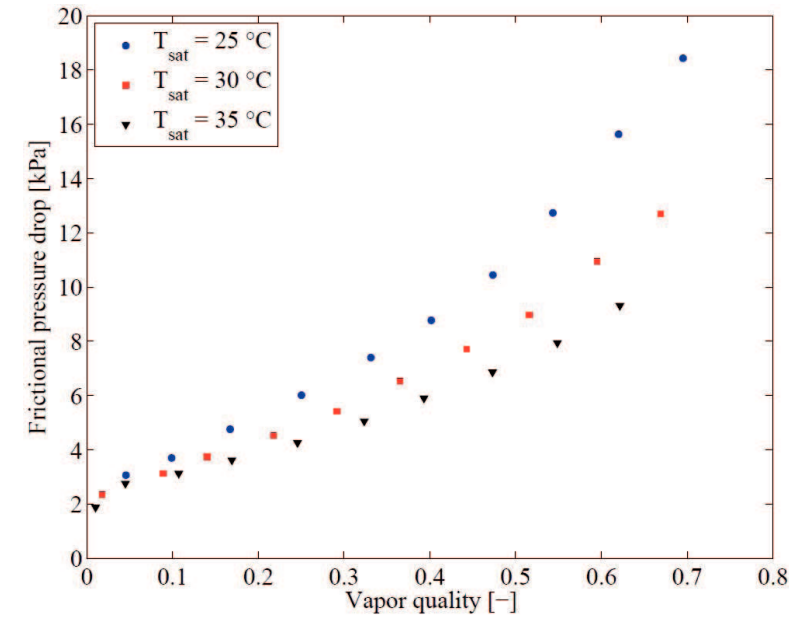

(b)

FIG. 10: Frictional pressure drop within the PHE versus vapor quality (a) effect of mass flux at $\mathrm{T}_{\text {sat }}=35^{\circ} \mathrm{C},(\mathbf{b})$ effect of saturation temperature (system pressure) at $\mathrm{G}=20 \mathrm{~kg} \mathrm{~m}^{-2} \mathrm{~s}^{-1}$ 
As observed in Fig. 10, two-phase frictional pressure drop grows rapidly with increasing vapor quality and mass flux due to the promotion of interfacial shear forces. In addition, the frictional pressure drops increase as the saturation temperatures is lowered (i.e., lower system pressures) since the liquid-vapor density difference increases and thus the vapor shear on the liquid phase increases. The trends in Fig. 10 are all similar to those one observes for two-phase flow inside tubes.

\subsection{Comparison with Several Existing and New Prediction Methods}

The current adiabatic two-phase pressure drop database includes a range of saturation temperatures from 19 to $35^{\circ} \mathrm{C}$, mass fluxes from 10 to $40 \mathrm{~kg} \mathrm{~m}^{-2} \mathrm{~s}^{-1}$, and vapor qualities from 0.02 to $0.8 \mathrm{using} \mathrm{R} 245 \mathrm{fa}$.

Several of the most widely used PHE correlations were evaluated and compared to the present experimental data, which involves extrapolation of these existing methods to this fluid and plate size/geometry. Then, the present experimental data were also correlated, based on a homogeneous approach [Eq. (21)]:

$$
f_{t p}=7.05 \times 10^{5} \operatorname{Re}_{e q}^{-2.476}+1.474
$$

Furthermore, the two-phase frictional pressure drop data were compared to the Chisholm (1967) method in order to find the optimized $C$ parameter based on best curve fitting to the present database and single-phase friction factor proposed in Eq. (23), leading to a constant of 14.14:

$$
\varphi_{l}^{2}=1+\frac{14.14}{\mathrm{X}_{t t}}+\frac{1}{\mathrm{X}_{t t}^{2}}
$$

Figure 11 shows a comparison between the experimental frictional pressure drops and the prediction methods. In addition, the relative mean absolute error (MAE) and the percentage of predictions which fall within $\pm 30 \%$ with respect to the corresponding experimentally measured frictional pressure drops were computed to provide a quantitative scheme to evaluate the prediction methods.

Table 4 summarizes the statistical comparison between the present data and the prediction methods. The Khan et al. (2014) method worked quite well while the other methods did not, probably because the current corrugation depth of $1 \mathrm{~mm}$ is much less than those previously tested (typically 3-5 mm) or it might be due to their being developed from diabatic pressure drops data (i.e., frictional pressure drop gradients were not constant along the PHE as the vapor quality changed continuously from the PHE inlet to outlet).

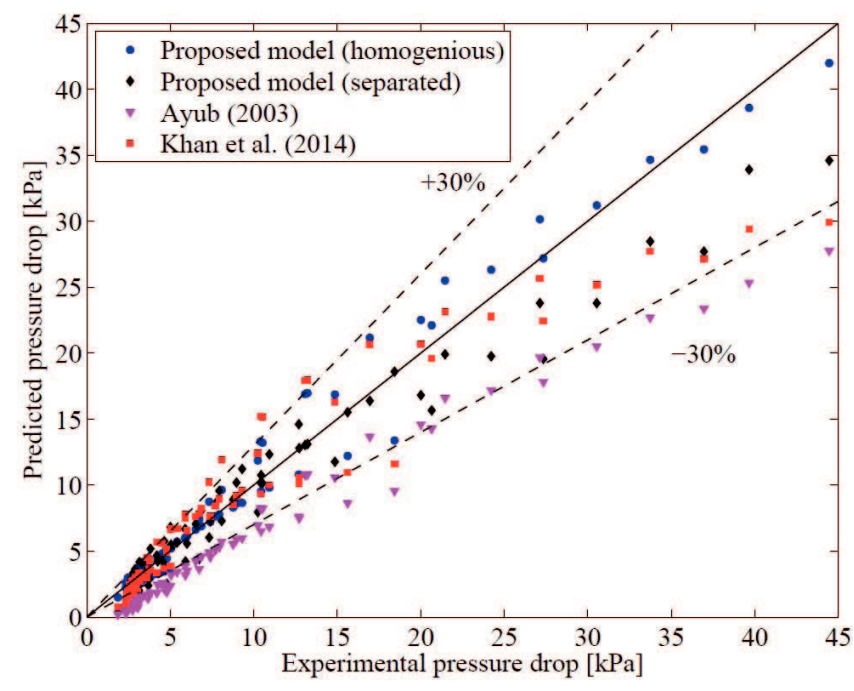

FIG. 11: Two-phase adiabatic frictional pressure drop data compared to the prediction methods 
TABLE 4: Summary of comparison between experimental data and prediction methods

\begin{tabular}{|c|c|c|c|}
\hline \multirow{2}{*}{ Correlations } & \multicolumn{3}{|c|}{ Statistics $^{*}$} \\
\cline { 2 - 4 } & $\mathrm{ME}^{a}$ & $\mathrm{MAE}^{b}$ & $\pm 30 \%^{c}$ \\
\hline Ayub (2003) & -47.4 & 47.4 & 14.9 \\
\hline Han et al. (2003) & 271.1 & 271.1 & 0 \\
\hline Huang et al. (2012) & 225.8 & 225.8 & 0 \\
\hline Longo (2012) & 195.5 & 196 & 20.3 \\
\hline Khan et al. (2014) & -2 & 19.4 & 75.7 \\
\hline Proposed model [Eq. (25)] & -10.9 & 20.6 & 77 \\
\hline Proposed model [Eq. (24)] & 0.7 & $\mathbf{1 1 . 4}$ & $\mathbf{1 0 0}$ \\
\hline
\end{tabular}

${ }^{a}$ Percentage of mean error, $(100 / n) \sum_{1}^{n}\left(\Delta p_{\exp }-\Delta p_{\text {pred }}\right) / \Delta p_{\exp }$, where $n$ is number of data.

${ }^{b}$ Percentage of mean absolute error, $(100 / n) \sum_{1}^{n}\left|\Delta p_{\exp }-\Delta p_{\text {pred }}\right| / \Delta p_{\exp }$, where $n$ is number of data.

${ }^{c}$ Percentage of experimental data captured within $\pm 30 \%$.

\subsection{Local Two-Phase Pressure Drop Based on the IR Camera Measurements}

Next, a series of adiabatic two-phase flow tests was performed to visualize and analyze the local pressure field within the PHE. Figure 12 represents a sample of two-phase pressure map (pressure field) extracted from the corresponding thermal map (IR camera temperature measurements), together with the corresponding widthwise (normal to flow direction) and lengthwise (along flow direction) pressure profiles.

As observed in Fig. 12, the widthwise pressure profiles in each window were found to be rather uniform, which apparently confirmed the liquid-vapor flow is well distributed through a cross section of the channels inside the PHE. For example, in Fig. 12(c) the widthwise variation in saturation pressure is only about $0.5 \%$ of the local pressure, i.e., within the sensitivity of the IR camera itself. Moreover, the local pressures declined along the plate length at the beginning mainly due to the contribution of static and frictional pressure drops; nevertheless, it increased later (on the last two openings) as the flow is influenced by the outlet restriction and the flow collector. Therefore, the effect of the outlet on the pressure field was found to be considerable and this local trend is not included in any of the prediction methods above. According to the observations during the adiabatic two-phase pressure drop tests, either a linear pressure drop or a two-phase pressure drop scheme (e.g., an existing prediction method from the literature or that has been proposed in the previous section) were found to be not applicable to estimate the correct trend of the pressure field in the PHE. Therefore, the frictional pressure drops within the PHE were correlated individually for each set of consecutive openings (from the inlet to the outlet) based on the data obtained from IR measurements during adiabatic two-phase tests covering the applicable range of flow boiling tests. Then, these results have been used to determine the pressure field and thus refrigerant saturation temperatures on flow boiling tests (in Part II) in order to reduce the data and obtain the local pixel-by-pixel heat transfer coefficients (presented in Part II).

\section{CONCLUSIONS}

A new promising compact Plate Heat Exchanger (PHE) was fabricated and its two-phase thermal and hydraulic performance were investigated in detail. The PHE prototype comprised two extremely thin corrugated plates with a corrugation depth of $1 \mathrm{~mm}$ and a chevron angle $65^{\circ}$, which were made into a single-pass PHE prototype. A series of single- and two-phase adiabatic tests was conducted to investigate frictional pressure drops within the compact prototype plate heat exchanger. The results are summarized as follows: 


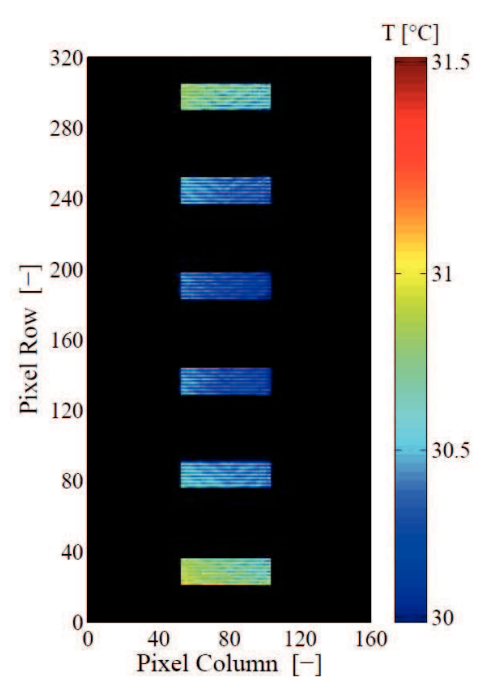

(a)

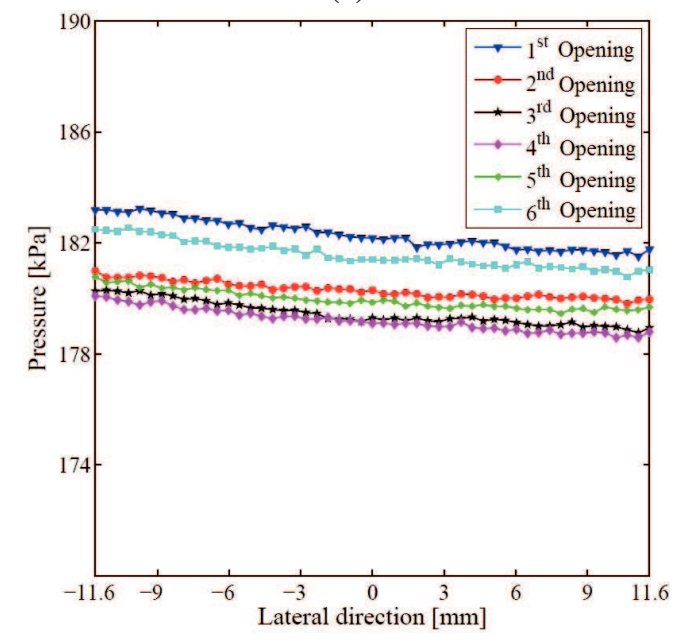

(c)

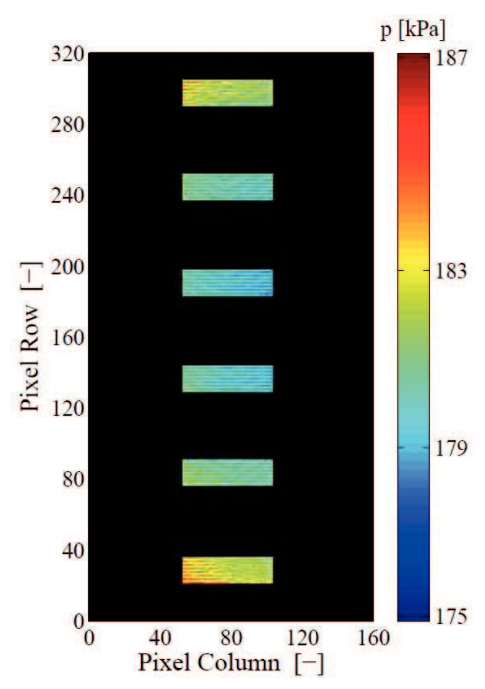

(b)

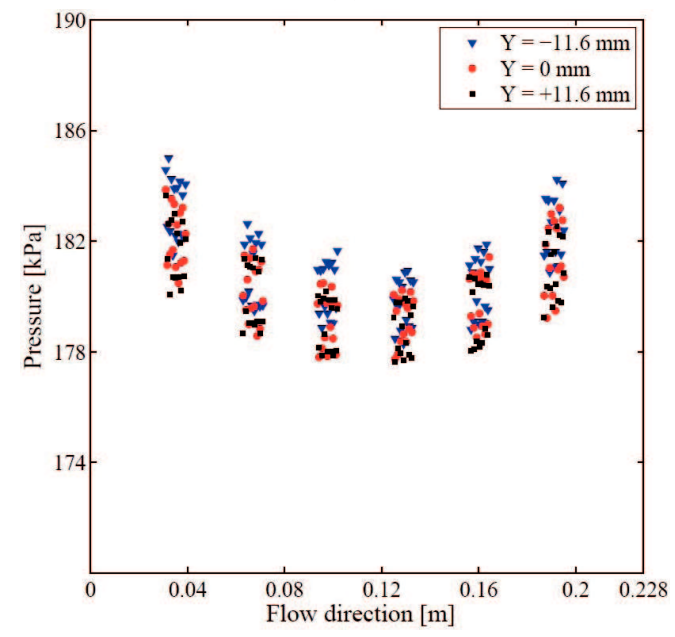

(d)

FIG. 12: Two-phase adiabatic test results at $\mathrm{G}=10 \mathrm{~kg} \mathrm{~s}^{-1} \mathrm{~m}^{-2}, \mathrm{~T}_{\text {sat }}=30^{\circ} \mathrm{C}$, and $\mathrm{x}=0.57$ (a) measured temperature by IR camera (b) refrigerant pressure field obtained from IR measurements (c) widthwise pressure profiles (d) lengthwise pressure profiles

- In general, the two-phase frictional pressure drops increased as vapor quality and mass flow rate rise, while it decreased with an increase in the saturation temperature. Based on the present experimental data, it is realized that all trends were similar to those observed for two-phase flow inside tubes.

- An experimental approach (not yet applied to PHEs) was introduced in this study to investigate high-resolution local (pixel-by-pixel) pressure drops of R245fa within a compact prototype PHE, using an IR camera.

- Several of the most widely used prediction methods for frictional pressure drop within PHEs were evaluated with respect to the current experimental database.

- New prediction methods were proposed to reproduce the single-phase and two-phase adiabatic frictional pressure drops data of the present PHE. 
- The influences of outlet restriction and flow collector on the pressure field were shown to be considerable, with pressure recovery evident as the two-phase flow headed toward the outlet. According to the observation during the adiabatic two-phase pressure drop tests, neither a linear pressure drop nor a two-phase pressure drop scheme was found to be applicable to estimate the correct trend of the pressure field in the PHE.

\section{ACKNOWLEDGMENTS}

The authors wish to thank US Office of Naval Research (in particular the program director, Mark Spector) for the financial support provided for the project N000141210398.

\section{REFERENCES}

Akers, W. W., Deans, H. A., and Crosser, O. K., Condensation heat transfer within horizontal tubes, Chem. Eng. Process Symp. Series, vol. 55, no. 29, pp. 171-176, 1959.

Ayub, Z. H., Plate heat exchanger literature survey and new heat transfer and pressure drop correlations for refrigerant evaporators, Heat Transfer Eng., vol. 24, no. 5, pp. 3-16, 2003.

Bergles, A. E., Manglik, R. M., and Kraus, A. D., Plate Heat Exchangers for Process Industry Applications: Enhanced ThermalHydraulic Characteristics of Chevron Plates. Process, Enhanced, and Multiphase Heat Transfer, Begell House, New York, pp. 267-276, 1996.

Chisholm, D., A theoretical basis for the Lockhart-Martinelli correlation for two-phase flow, Int. J. Heat Mass Transfer, vol. 10, no. 12, pp. 1767-1778, 1967.

Dukler, A. E., Wicks, M., and Cleveland, R. G., Frictional pressure drop in two-phase flow: B. An approach through similarity analysis, AIChE J., vol. 10, no. 1, pp. 44-51, 1964.

Han, D. H., Lee, K. J., and Kim, Y. H., Experiments on the characteristics of evaporation of R410a in brazed plate heat exchangers with different geometric configurations, Appl. Thermal Eng., vol. 23, no. 10, pp. 1209-1225, 2003.

Heavner, R. L., Kumar, H., and Wanniarachchi, A. S., Performance of an industrial plate heat exchanger: Effect of Chevron angle, AIChE Symposium Series, AIChE, New York, vol. 89, pp. 262-267, 1993.

Huang, J., Sheer, T., and Bailey-McEwan, M., Heat transfer and pressure drop in plate heat exchanger refrigerant evaporators, Int. J. Refrigeration, vol. 35, no. 2, pp. 325-335, 2012.

Kaka, S., Liu, H., and Pramuanjaroenkij, A., Heat Exchangers: Selection, Rating, and Thermal Design, 2nd ed., CRC Press, Boca Raton, FL, 2002.

Khan, M. S., Khan, T. S., Chyu, M. C., and Ayub, Z. H., Evaporation heat transfer and pressure drop of ammonia in a mixed configuration chevron plate heat exchanger, Int. J. Refrigeration, vol. 41, pp. 92-102, 2014.

Khan, T. S., Khan, M. S., Chyu, M. C., and Ayub, Z. H., Experimental investigation of evaporation heat transfer and pressure drop of ammonia in a $60^{\circ}$ chevron plate heat exchanger, Int. J. Refrigeration, vol. 35, no. 2, pp. 336-348, 2012.

Kumar, H., The plate heat exchanger: Construction and design, Institute of Chemical Engineering Symp. Series, no. 86, pp. 1275$1288,1984$.

Longo, G. A., Vaporisation of the low Gwp Refrigerant Hfo1234yf inside a brazed plate heat exchanger, Int. J. Refrigeration, vol. 35, no. 4, pp. 952-961, 2012.

Martin, H., A theoretical approach to predict the performance of chevron-type plate heat exchangers, Chem. Eng. Process.: Process Intensification, vol. 35, no. 4, pp. 301-310, 1996.

Nilpueng, K. and Wongwises, S., Two-phase gas-liquid flow characteristics inside a plate heat exchanger, Exp. Therm. Fluid Sci., vol. 34, no. 8, pp. 1217-1229, 2010.

Shah, R. K. and Focke, W. W., Plate Heat Exchangers and Their Design Theory. Heat Transfer Equipment Design, R. K. Shah, E. C. Subbarao, and R. A. Mashelkar, eds., Hemisphere Publishing, Washington, DC, pp. 227-254, 1988.

Tribbe, C. and Mller-Steinhagen, H. M., Gas/liquid flow in plate-and-frame heat exchangers - Part II: Two-phase multiplier and flow pattern analysis, Heat Transfer Eng., vol. 22, no. 1, pp. 12-21, 2001. 